\title{
An Efficient Metal-Free Hydrophilic Carbon as a Counter Electrode for Dye-Sensitized Solar Cells
}

\author{
Mojgan Kouhnavard, ${ }^{1}$ Norasikin Ahmad Ludin, ${ }^{2}$ Babak Vazifehkhah Ghaffari, ${ }^{1}$ \\ Kamaruzzaman Sopian, ${ }^{2}$ Norshazlinah Abdul Karim, ${ }^{2}$ and Mikio Miyake ${ }^{1}$ \\ ${ }^{1}$ Malaysia-Japan International Institute of Technology, Universiti Teknologi Malaysia (UTM), 54100 Kuala Lumpur, Malaysia \\ ${ }^{2}$ Solar Energy Research Institute (SERI), Universiti Kebangsaan Malaysia (UKM), 43600 Bangi, Selangor, Malaysia
}

Correspondence should be addressed to Norasikin Ahmad Ludin; sheekeen@ukm.edu.my

Received 20 November 2015; Accepted 22 February 2016

Academic Editor: Prakash Basnyat

Copyright ( 2016 Mojgan Kouhnavard et al. This is an open access article distributed under the Creative Commons Attribution License, which permits unrestricted use, distribution, and reproduction in any medium, provided the original work is properly cited.

\begin{abstract}
This study presents a new cost-effective metal-free counter electrode (CE) for dye-sensitized solar cells (DSSCs). CE was prepared by doctor blading a hydrophilic carbon (HC) particle on a fluorine-doped tin oxide substrate. Thereafter, HC CE was characterized using X-ray diffraction, profilometry, four-point probe testing, and cyclic voltammetry. A $2 \mu \mathrm{m}$ thick HC CE revealed a comparable catalytic activity to that of the Pt electrode under the same experimental conditions. DSSC based on HC CE was analyzed and showed $J_{\mathrm{sc}}$ of $6.87 \mathrm{~mA} / \mathrm{cm}^{2}$ close to that of DSSC with Pt CE $\left(7.0 \mathrm{~mA} / \mathrm{cm}^{2}\right)$. More importantly, DSSC based on HC CE yielded a power conversion efficiency $(\eta)$ of $2.93 \%$ under AM 1.5 irradiation $\left(100 \mathrm{~mW} / \mathrm{cm}^{2}\right)$, which was comparable to that of DSSC based on standard Pt CE. These findings suggest that HC CE could be a promising CE for low-cost DSSCs.
\end{abstract}

\section{Introduction}

Silicon solar cell currently has the largest market share of $85 \%$ with conversion efficiency of approximately $25 \%$ [1]. However, this solar cell could not compete with conventional energy sources because of the high production cost that is mostly caused by the high purification process of the material. This issue motivated the scientist to find new methods to exploit the cheaper and highly efficient solar energy. Dyesensitized solar cells (DSSCs), as third-generation solar cells, are the major variant in this approach $[2,3]$. Since DSSC was invented by pioneers O'Regan and Grätzel in 1991 [4], this solar cell type has been introduced as one of the low-cost and highly efficient solar cells because of the availability of materials, low cost, and simple fabrication processes [5-9]. Over the last 10 years, the highest efficiency of DSSCs ever reported is approximately $12 \%[10,11]$.

In principle, DSSCs comprise three main components, namely, photoanode, counter electrode (CE), and electrolyte (commonly iodide), as shown in Figure 1. The photoanode is an oxide semiconductor, such as $\mathrm{TiO}_{2}$, deposited on a transparent conductive oxide (TCO) substrate. Thereafter, the
$\mathrm{TiO}_{2}$ surface is sensitized with dye (ruthenium complex), thereby contributing to the photon absorption and consequent electron injection. The electrolyte contains iodidetriiodide $\left(\mathrm{I}^{-} / \mathrm{I}_{3}{ }^{-}\right)$redox couples transferring the electrons from the photoanode to the CE. The Pt deposited on the TCO substrate is commonly used as a standard CE because of its high conductivity and catalytic activity toward the redox couples in the electrolyte.

This type of DSSC with current material has a total production cost between $\$ 36$ and $\$ 158 / \mathrm{m}^{2}$ [12]. The major contribution $(50 \%-60 \%)$ to the manufacturing cost of DSSCs arises from substrates, dyes, electrolytes, and Pt CEs. Therefore, the cost reduction improvement of DSSC is of immense interest [12]. Accordingly, researchers have been conducting studies to develop new sensitizers, photoanodes, redox couples, and CEs to fabricate cheap and efficient devices. Among these components, metal-free CEs are the best option to complement natural resources because $\mathrm{Pt}$ is expensive and rare. $\mathrm{Pt}$ corrosion in triiodide-containing solutions that generates platinum iodides, such as $\mathrm{PtI}_{4}$, is also reported [13].

In this subject matter, carbon based CEs, such as graphite $[14,15]$, carbon black [16], graphene [17], activated carbon 


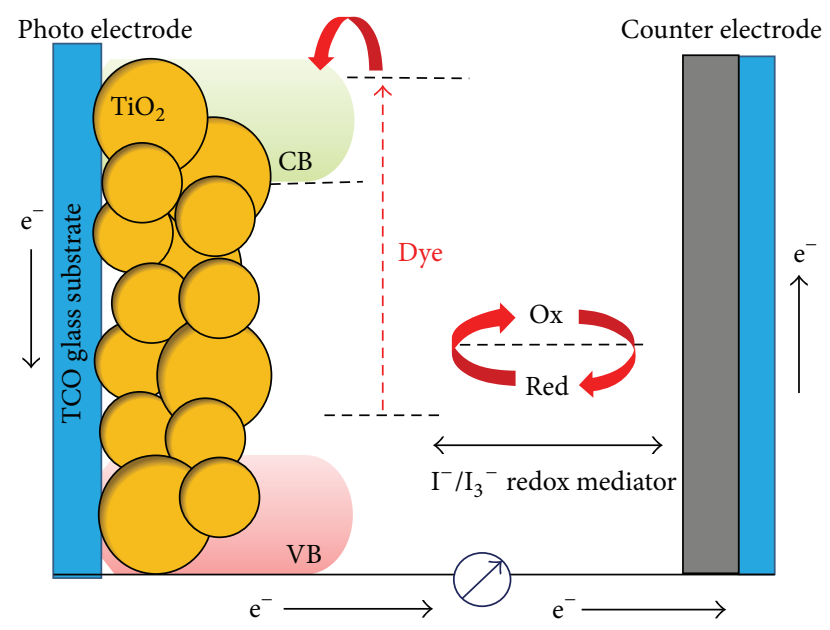

FIGURE 1: Schematic diagram of DSSC.

[18], and carbon nanotubes [19], are of significant research interest as potential low-cost replacements for Pt due to their high conductivity, large surface area, and catalytic activity toward the redox couples in the electrolyte [20].

Among them, graphite-based CEs often exhibit a low catalytic activity toward the redox couple. However, Veerappan et al. reported that submicrosized graphite electrode exhibits an improved performance by adjusting the particle size and film thickness [21]. Small graphite particles (flakes) are shown to have significant defects, that is, a considerable number of catalytic sites compared to micrographite ( $>20 \mu \mathrm{m})$.

The current research investigated a new low-cost hydrophilic carbon (HC) particle as CE to lead the commercialization of DSSC by making DSSCs more environment-friendly and less expensive device. The HC particle was produced using a simple electrolysis of a synthetic graphite plate [22]. Previous studies have reported that the HC particle has a good crystalline structure with an average particle size between $300 \mathrm{~nm}$ and $400 \mathrm{~nm}$ [22, 23].

\section{Experimental Method}

2.1. CE Preparation. The HC powder from Shion Co., Ltd. (Nagoya, Japan) was used to prepare HC CE. The HC paste was prepared by grinding $260 \mathrm{mg}$ of $\mathrm{HC}$ powder with $0.4 \mathrm{~mL}$ of $\mathrm{TiO}_{2}$ colloid, $0.8 \mathrm{~mL}$ of water, and $0.4 \mathrm{~mL}$ of $10 \%$ Triton X100 (Fisher Chemical) aqueous solution. The $\mathrm{TiO}_{2}$ colloid was prepared according to the procedures reported previously [24].

Prior to the deposition of $\mathrm{CE}$ on a fluorine-doped tin oxide (FTO) glass, FTOs with sheet resistance of approximately $8 \Omega / \mathrm{sq}$ (Pilkington) were cut into $1.5 \mathrm{~cm} \times 2 \mathrm{~cm}$. For the electrolyte inlet/outlet, two small holes were drilled in the middle of the substrate. The substrate was cleaned in an ultrasonic bath with acetone and isopropanol for $20 \mathrm{~min}$ in each step followed by drying under nitrogen flow.

Using the doctor blade technique, the paste was spread on the FTO substrate using a double scotch tape and a glass rod followed by sintering in a cylinder furnace at $450^{\circ} \mathrm{C}$ at air ambient for $30 \mathrm{~min}$. For comparison, a thin layer of Pt paste (Dyesol Co.) was deposited on the entire surface of the FTO glass substrate using the same technique to deposit HC CE. This process was followed by sintering at $450^{\circ} \mathrm{C}$ for $30 \mathrm{~min}$.

2.2. DSSC Preparation. Prior to the photoanode deposition, the FTO substrate with sheet resistance of $15 \Omega /$ sq was cut, cleaned, and dried similar to the description for $\mathrm{HC} \mathrm{CE}$ in Section 2.1. Thereafter, the 90- $\mathrm{T}$ transparent titania paste (Dyesol Co.) was deposited on the conductive side of the FTO glass using the doctor blade technique $[25,26]$. After deposition, the layer was annealed using a cylinder furnace set at $500^{\circ} \mathrm{C}$ in air for $30 \mathrm{~min}$. The second layer of $\mathrm{TiO}_{2}-$ WER-40 (Dyesol Co.) was further deposited on top of the first layer as a scattering layer. The second layer was annealed using similar technique and temperature. $\mathrm{TiCl}_{4}$ treatment was performed by dipping the freshly sintered $\mathrm{TiO}_{2}$ films into an aqueous solution of $40 \mathrm{mM}$ of $\mathrm{TiCl}_{4}$ tetrahydrofuran (Sigma Aldrich) at $70^{\circ} \mathrm{C}$ for $30 \mathrm{~min}$. The $\mathrm{TiO}_{2}$ film was rinsed in deionized water and ethanol and dried under nitrogen flow. After the $\mathrm{TiCl}_{4}$ treatment, the $\mathrm{TiO}_{2}$ film was sintered at $500^{\circ} \mathrm{C}$ for $30 \mathrm{~min}$. The sintered electrode was maintained at $100^{\circ} \mathrm{C}$ for approximately $30 \mathrm{~min}$ before immersing into the dye solution. The $\mathrm{TiO}_{2}$ film was then soaked for approximately $24 \mathrm{~h}$ at room temperature in a dye solution containing $0.3 \mathrm{mM}$ of N719 (Solaronix) in acetonitrile and tert-butyl alcohol (1:1 volume ratio). After sensitization, the sensitized $\mathrm{TiO}_{2}$ was rinsed with isopropanol and dried under nitrogen flow. To fabricate a DSSC, the photoanode and CE (Pt) with an active area of $1 \mathrm{~cm}^{2}$ were encapsulated using a piece of hot melt film (Surlyn 1702; Solaronix) with a thickness of $25 \mu \mathrm{m}$ and melted using hot press at $120^{\circ} \mathrm{C}$ for $20 \mathrm{~s}$. A similar fabrication procedure was applied to assemble a photoanode with HC CE; the only difference was the sealant thickness, which was $90 \mu \mathrm{m}$. After sealing, two drops of iodine-based electrolyte were injected between the two electrodes through the predrilled holes on the FTO glass. Thereafter, the holes were sealed using the same sealant with a small glass slide to cover the hole and pressed for $10 \mathrm{~s}$ at $120^{\circ} \mathrm{C}$. In this research, a liquid electrolyte based on iodine was prepared by dissolving $0.06 \mathrm{M}$ of iodine (Sigma Aldrich) in $0.5 \mathrm{M}$ of 4-tert-butyl pyridine (Sigma Aldrich) and $0.5 \mathrm{M}$ of 1-butyl3 methyl imidazolium iodide in acetonitrile solvent and 1butyl-3 methyl imidazolium iodide (>98\%; io.li.tec.).

\section{Measurements}

The HC CE crystal structure before and after the annealing treatment was identified through X-ray diffraction (XRD; Brucker) with $\mathrm{Cu}-\mathrm{K} \alpha$ radiation $(\lambda=1.5418 \AA)$. The thickness and surface morphologies, both in top and in cross-sectional views of a sintered $\mathrm{HC}$ CE, were identified using a field emission scanning electron microscope (FESEM; JEOL, JSM7000F). The HC CE atomic ratio was recorded using the energy dispersive X-ray spectroscopy (EDX) analysis. Surface profilometry (Brucker) was performed to determine the thickness and roughness of CEs. The sheet resistance of HC CE was measured using a four-point probe (Keithley, 2400 auto calculating) resistivity test system. Cyclic voltammetry 


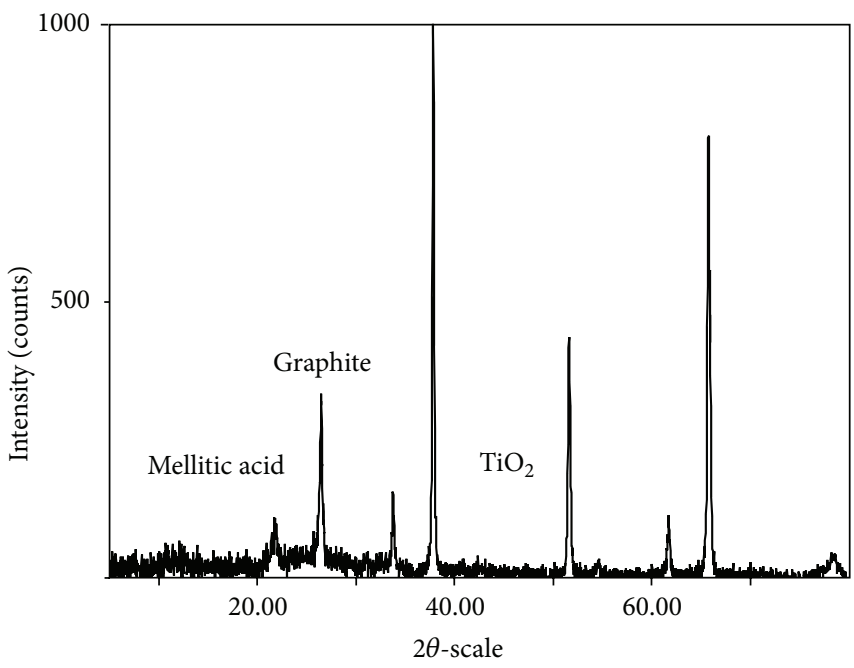

(a)

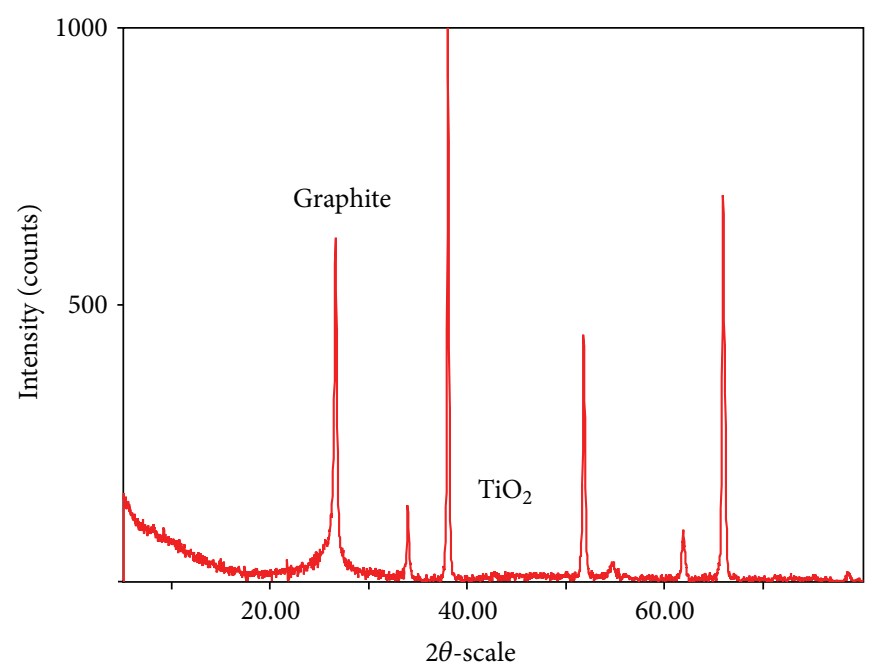

(b)

Figure 2: The X-ray diffraction pattern of (a) preheated and (b) sintered HC film.

(CV) analysis was conducted using Solartron with three electrode configurations, including $\mathrm{Ag} / \mathrm{AgCl}(3 \mathrm{M} \mathrm{KCl})$ used as a reference electrode, $\mathrm{Pt}$ wire as $\mathrm{CE}$, and $\mathrm{Pt}$ and $\mathrm{HC}$ films as working electrodes, in an acetonitrile solution containing $10 \mathrm{mM}$ of LiI, $1 \mathrm{mM}$ of $\mathrm{I}_{2}$, and $0.1 \mathrm{M}$ of $\mathrm{LiClO}_{4}$ as supporting electrolytes at a scan rate of $50 \mathrm{mV} / \mathrm{s}$. The active exposed surface area for CEs was $1 \mathrm{~cm}^{2}$. To measure the DSSC performance, current-voltage $(I-V)$ characteristic analysis of a light exposed cell was performed using a Keithley model 2400 source-measuring unit. A solar simulator with 150 xenon lamps served as the light source with light intensity of $100 \mathrm{~mW} / \mathrm{cm}^{2}$.

\section{Results and Discussion}

In $\mathrm{CE}$, triiodide ions $\left(\mathrm{I}_{3}{ }^{-}\right)$, which are produced by the reduction of oxidized sensitizer, are rereduced to $\mathrm{I}^{-}$ions. For this reaction to occur, a CE must have a high electrocatalytic activity [27]. A high crystalline structure is considerably preferable for achieving a high electrocatalytic activity, thereby reducing internal defects, decreasing electron-loss pathway, and subsequently increasing energy conversion efficiency [28]. XRD measurement was conducted in this study to identify the HC CE crystal structure before and after annealing treatment, as shown in Figure 2. The HC film has a good crystalline structure that contains graphite and mellitic acid (benzene hexacarboxylic acid: $\mathrm{C}_{12} \mathrm{H}_{6} \mathrm{O}_{12}$ ) with hexagonal and orthorhombic phase shapes, respectively. Further, the amorphous structures of $\mathrm{TiO}_{2}$ could be observed with monoclinic phase shape. The peak of (002) at $2 \theta=26.4^{\circ}$ contributed to the graphite, whereas other peaks well fitted with those of cassiterite (referring to FTO). No changes were observed in the position of the graphite peaks after annealing. However, the crystallinity of graphite intensified from 215 counts to 663 counts after annealing.

Figure 3 displays the top and cross-sectional views of the FESEM images of the HC film on a FTO substrate along with its atomic ratio. The inset (Figure 3(a)) shows the highmagnification image of the film. The HC film uniformly covered the substrate surface, thereby resulting in a crackfree HC film. A highly porous structure of the film with spherical HC particle was also observed. The cross-sectional view (Figure 3(b)) indicates thicknesses of 2.15 and $1 \mu \mathrm{m}$ for the HC film and FTO covered glass substrate, respectively.

The atomic ratio of the $\mathrm{HC}$ film was estimated through EDX analysis (Figure 3(c)). The result showed that HC CE mostly contained carbon $(\approx 80 \%)$ with $4 \%$ titanium and $16 \%$ oxygen. Annealing treatment of the HC film was also performed under nitrogen flow to reduce the oxygen ratio in the film. However, this approach caused the carbon layer to fall off from the FTO substrate. It can be suggested that the oxygen functional groups in the $\mathrm{HC}$ film improved the adhesion between the FTO substrate and the HC layer, as well as among the HC particles.

Carbonaceous materials with rough surface provide considerable reduction sites or the surface area for $\mathrm{CE}$ to react with electrolytes, thereby resulting in the electrode's high catalytic activity [29]. Film thickness is also an important factor in determining the CE properties because it affects both the conductivity and catalytic activity of the electrode $[30,31]$. Profilometry measurement was conducted to identify the surface roughness and thickness of HC CE. The results showed average roughness and thickness of 0.9 and $2.09 \mu \mathrm{m}$, respectively, for HC CE, whereas they were 180 and $240 \mathrm{~nm}$, respectively, for the $\mathrm{Pt}$ electrode prepared under the same condition. The layer thickness identified by the profilometry measurement was nearly in agreement with the FESEM results showing a thickness of $2.15 \mu \mathrm{m}$ for the HC film.

Electrical conductivity and catalytic activity are two major factors that significantly affect the CE performance in DSSCs. Therefore, large conductivity and catalytic activity could result in higher energy conversion efficiency. The sheet resistance of $\mathrm{HC} \mathrm{CE}$ was recorded using the four-point probe technique. The sheet resistivity of $\mathrm{HC}$ CE was determined to 


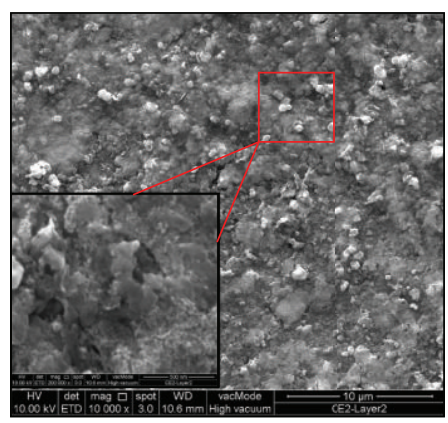

(a)

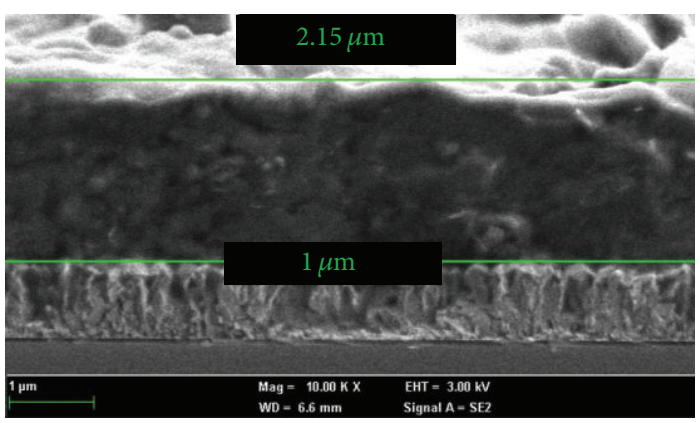

(b)

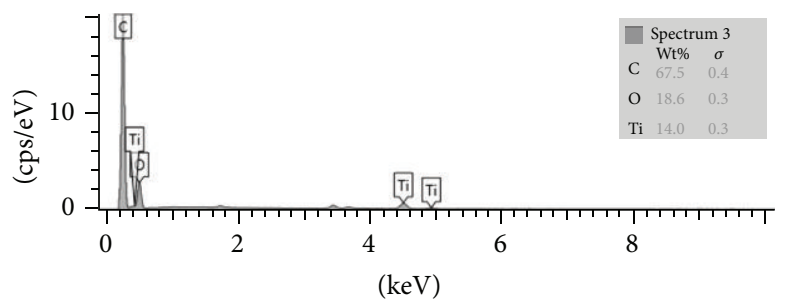

\begin{tabular}{lccccc}
\hline Element & Line type & $\begin{array}{c}\text { Apparent } \\
\text { concentration }\end{array}$ & $\mathrm{Wt} \%$ & $\mathrm{Wt} \% \sigma$ & Atomic\% \\
\hline $\mathrm{C}$ & K series & 7.57 & 67.47 & 0.37 & 79.46 \\
$\mathrm{O}$ & K series & 2.13 & 18.57 & 0.30 & 16.42 \\
$\mathrm{Ti}$ & K series & 1.43 & 13.96 & 0.33 & 4.12 \\
Total: & & & 100.00 & & 100.00 \\
\hline
\end{tabular}

(c)

FIgURE 3: (a) Top view and (b) cross-sectional view of FESEM image for the HC film on FTO covered glass substrate (c) weight and atomic ratio of $\mathrm{HC}$ film estimated by EDX analysis.

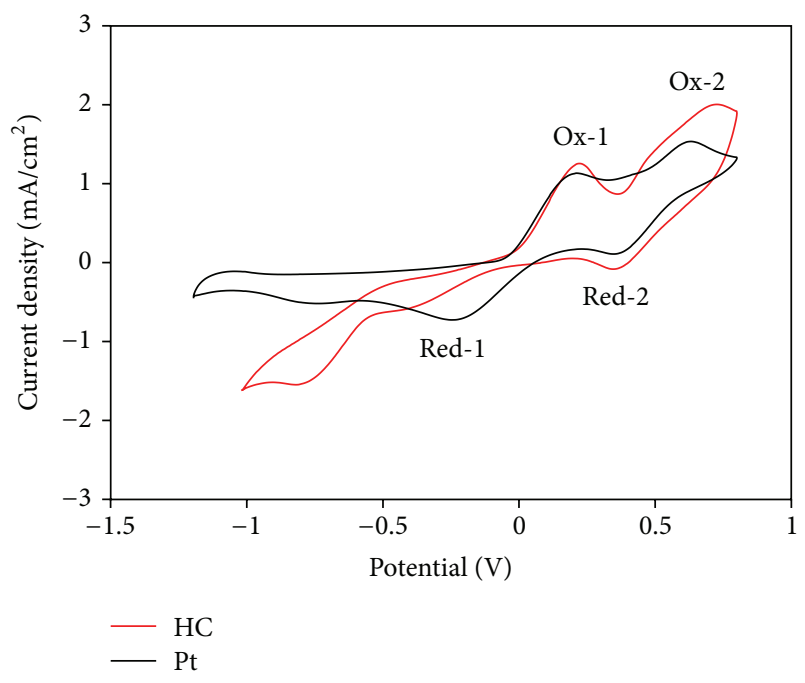

Figure 4: Cyclic voltagramms of Pt and HC film obtained at a scan rate of $50 \mathrm{mV} / \mathrm{s}$ electrode.

be slightly higher than that of the Pt electrode, with values of 7.8 and $3.17 \Omega /$ sq, respectively.

$\mathrm{CV}$ was also performed to characterize the catalytic activity of HC CE toward the redox couples. Figure 4 shows the cyclic voltammogram of $\mathrm{Pt}$ and HC CEs, in which the potential interval ranged from $-1 \mathrm{~V}$ to $1 \mathrm{~V}$ versus $\mathrm{Ag} / \mathrm{AgCl}$ at a scan rate of $50 \mathrm{mV} / \mathrm{s}$. In the $\mathrm{CV}$ curves, two pairs of oxidation and reduction peaks (Ox-1/Red-1 and Ox-2/Red-2, respectively, as labeled in Figure 4) were resolved well in the range from $-1 \mathrm{~V}$ to $1 \mathrm{~V}$. The left and right pairs are assigned to (1) and (2), respectively. Consider the following:

$$
\begin{aligned}
& \mathrm{I}_{3}{ }^{-}+2 \mathrm{e}^{-} \longleftrightarrow 3 \mathrm{I}^{-} \\
& 3 \mathrm{I}_{2}+2 \mathrm{e}^{-} \longleftrightarrow 2 \mathrm{I}_{3}^{-}
\end{aligned}
$$

The peaks obtained at the positive side are known as anodic peaks, which refer to the oxidation of iodide and triiodide. The peaks obtained at the negative section are the cathodic peaks, which correspond to the reduction of triiodide [32]. Consequently, the overall feature of $\mathrm{CV}$ for the $\mathrm{HC}$ electrode was similar to that for the Pt electrode, whereas $\mathrm{HC} \mathrm{CE}$ represented a slightly faster oxidation rate $(\mathrm{Ox}-1$ and $\mathrm{Ox}-2)$. In detail, HC CE exhibited Ox-1 and Ox-2 of $0.70 \mathrm{~mA} / \mathrm{cm}^{2}$ and $0.45 \mathrm{~mA} / \mathrm{cm}^{2}$, respectively, whereas they were $0.68 \mathrm{~mA} / \mathrm{cm}^{2}$ and $0.40 \mathrm{~mA} / \mathrm{cm}^{2}$, respectively, for the Pt electrode. HC CE revealed a lower reduction current density (Red-1) than that of the Pt electrode $\left(0.75 \mathrm{~mA} / \mathrm{cm}^{2}\right)$, thereby contributing to a lower catalytic activity of $\mathrm{HC}$ CE because of the few catalytic sites for triiodide reduction. Nevertheless, a comparable catalytic activity to the Pt electrode was observed for HC CE, which could be attributed to the electrode's porous structure and large surface area, mainly favored by the addition of $\mathrm{TiO}_{2}$ colloid to the HC particle, as reported earlier [24]. 
TABLE 1: Photovoltaic parameters of the cells shown in Figure 6. The errors are the SD values calculated from three measurements of three different devices for each film.

\begin{tabular}{lccccc}
\hline $\mathrm{CE}$ & $R_{s}(\Omega)$ & $J_{\mathrm{sc}}\left(\mathrm{mA} / \mathrm{cm}^{2}\right)$ & $V_{\text {oc }}(\mathrm{V})$ & $\mathrm{FF} \%$ & \multicolumn{2}{c}{${ }^{2}$} \\
\hline $\mathrm{Pt}$ & $41.02 \pm 1.20$ & $7.0 \pm 0.1$ & $0.75 \pm 0.00$ & $68.71 \pm 0.12$ & $3.57 \pm 0.06$ \\
$\mathrm{HC}$ & $43.94 \pm 0.78$ & $6.87 \pm 0.11$ & $0.74 \pm 0.00$ & $57.26 \pm 0.62$ & $2.93 \pm 0.06$ \\
\hline
\end{tabular}

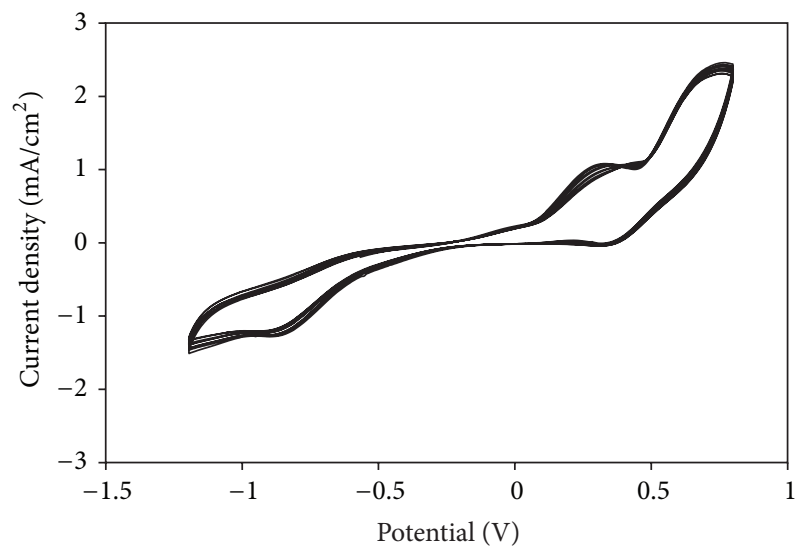

FIGURE 5: 50 successive cycles of HC CE obtained at a scan rate of $50 \mathrm{mV} / \mathrm{s}$.

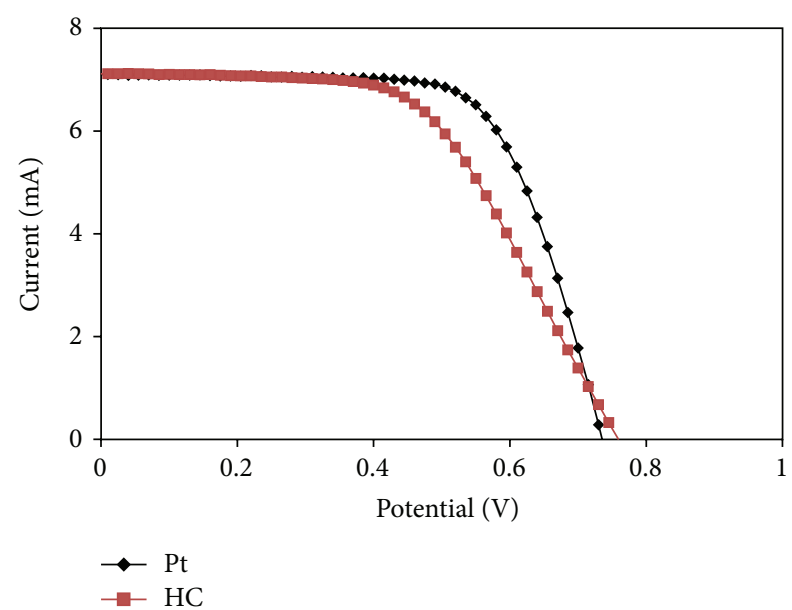

FIgURE 6: Comparison of $I-V$ characteristics of DSSCs fabricated with Pt and HC CE under 1 sun illumination (AM 1.5, $100 \mathrm{~mW} / \mathrm{cm}^{2}$ ).

A total of 50 consecutive $\mathrm{CV}$ scans were performed to investigate the stability of $\mathrm{HC} \mathrm{CE}$. Figure 5 shows the result. The shapes of the curves presented no evident change in the consecutive scans, thereby exhibiting stable anodic and cathodic peak currents. Thus, HC CE had reasonable chemical stability and was firmly deposited on the FTO substrate.

Three complete DSSC devices based on each $\mathrm{HC}$ and $\mathrm{Pt}$ CE were tested to study the performance of DSSC using the $I-V$ measurement. Thereafter, the average value and standard deviation among different devices were calculated. Figure 6 shows the $I-V$ curves of DSSC using HC and Pt CEs. The measurement was conducted under an AM 1.5 solar simulator at $100 \mathrm{~mW} / \mathrm{cm}^{2}$ intensity.
Table 1 presents a summary of the detailed photovoltaic parameters of $\mathrm{HC}$ and Pt CEs, including short current density $\left(J_{\mathrm{sc}}\right)$, open-circuit voltage $\left(V_{\mathrm{oc}}\right)$, fill factor $(\mathrm{FF})$, cell efficiency $(\eta)$, and series resistance $\left(R_{s}\right)$. Note that DSSC using HC CE had $J_{\mathrm{sc}}$ of $6.87 \mathrm{~mA} / \mathrm{cm}^{2}$, which approximated that of DSSC with a Pt CE of $7.0 \mathrm{~mA} / \mathrm{cm}^{2}$. Comparable $J_{\text {sc }}$ was favored by the high surface roughness of $\mathrm{HC} \mathrm{CE}$, thereby resulting in a comparable efficiency of $2.93 \%$ to the Pt-based DSSC with efficiency of $3.57 \%$.

The lower cell efficiency using HC CE was mainly caused by its lower FF than that of the Pt-based cells. The lower FF was probably caused by the higher series resistance of HC CE (41.02 $\Omega$ ) than that of the Pt-based cell, which may be attributed to the significantly larger thickness of HC CE. Although a high thickness substantially increased the surface area for triiodide reduction, such characteristic also increased the average electron transport length before reaching the site for triiodide reduction, as well as the internal series resistance [33].

Nevertheless, HC CE has its own advantages of having a large surface area and high porosity that could compensate the effects of the higher series resistance, thereby resulting in comparable efficiency to that of the Pt-based cell.

Moreover, no apparent difference in $V_{\text {oc }}$ of Pt- and HCbased DSSCs was observed. It should be also noted that these results were not high compared with the results reported in previous studies. The objective of the current research was not to obtain an optimized device but to conduct a comparative study on alternative CE to replace Pt.

\section{Conclusion}

This study investigated a new type of CE for triiodide reduction in DSSCs. CE was prepared using $\mathrm{HC}$ particle and successfully deposited on an FTO glass substrate using the doctor blade technique. The results indicated HC CE's high surface roughness and good conductivity and catalytic activity. Furthermore, DSSC with HC CE exhibited a comparable photovoltaic performance with an efficiency of $2.93 \%$ to DSSCs with Pt CE (3.57\%). The low photovoltaic performance was due to the high series resistance of the HC-based DSSC. Although the high-cost Pt CE still appears the best among the tested CEs and exhibited the best performance, the HC particle has the potential to be employed as a CE for DSSC and can be expected to lead to a low-cost and stable DSSC. Future studies can focus on advanced coating methods, such as screen printing, to attain stable and uniform coating for the considerably low resistivity of $\mathrm{HC}$ CE. Other conductive materials, such as polymers, nanocarbon, and CNT, may also be incorporated into the fabrication methods of $\mathrm{HC} \mathrm{CE}$ to 
increase the electrode's conductivity and catalytic activity, thereby making it highly comparable to Pt CE.

\section{Competing Interests}

The authors declare that there are no competing interests regarding the publication of this paper.

\section{Acknowledgments}

The authors acknowledge the financial assistance provided by Ministry of Higher Education Malaysia (LEP 2.0/14/ukm/ NT/03/1) and appreciate the contribution of the Solar Energy Research Institute (SERI) of Universiti Kebangsaan Malaysia.

\section{References}

[1] D. M. Chapin, C. S. Fuller, and G. L. Pearson, "A new silicon p-n junction photocell for converting solar radiation into electrical power," Journal of Applied Physics, vol. 25, no. 5, pp. 676-680, 1954.

[2] Y. Chiba, A. Islam, Y. Watanabe, R. Komiya, N. Koide, and L. Han, "Dye-sensitized solar cells with conversion efficiency of 11.1\%," Japanese Journal of Applied Physics, vol. 45, no. 24-28, pp. L638-L640, 2006.

[3] P. Poudel and Q. Qiao, "Carbon nanostructure counter electrodes for low cost and stable dye-sensitized solar cells," Nano Energy, vol. 4, pp. 157-175, 2014.

[4] B. O’Regan and M. Grätzel, "A low-cost, high-efficiency solar cell based on dye-sensitized colloidal $\mathrm{TiO}_{2}$ films," Nature, vol. 353, no. 6346, pp. 737-740, 1991.

[5] J. Chen, K. Li, Y. Luo et al., "Flexible carbon counter electrode for dye-sensitized solar cells," Carbon, vol. 47, no. 11, pp. 27042708, 2009.

[6] L. L. Chen, J. Liu, J. B. Zhang, X. W. Zhou, X. L. Zhang, and Y. Lin, "Low temperature fabrication of flexible carbon counter electrode on ITO-PEN for dye-sensitized solar cells," Chinese Chemical Letters, vol. 21, no. 9, pp. 1137-1140, 2010.

[7] S. Ito, N.-L. C. Ha, G. Rothenberger et al., "High-efficiency (7.2\%) flexible dye-sensitized solar cells with Ti-metal substrate for nanocrystalline- $\mathrm{TiO}_{2}$ photoanode," Chemical Communications, no. 38, pp. 4004-4006, 2006.

[8] L. Kavan, J. H. Yum, and M. Grätzel, "Optically transparent cathode for dye-sensitized solar cells based on graphene nanoplatelets," ACS Nano, vol. 5, no. 1, pp. 165-172, 2011.

[9] M. Sibiński, M. Jakubowska, K. Znajdek, M. Słoma, and B. Guzowski, "Carbon nanotube transparent conductive layers for solar cells applications," Optica Applicata, vol. 41, no. 2, pp. 375381, 2011.

[10] A. Yella, H.-W. Lee, H. N. Tsao et al., "Porphyrin-sensitized solar cells with cobalt (II/III)-based redox electrolyte exceed 12 percent efficiency," Science, vol. 334, no. 6056, pp. 629-634, 2011.

[11] M. Grätzel, "Dye-sensitized solar cells," Journal of Photochemistry and Photobiology C: Photochemistry Reviews, vol. 4, no. 2, pp. 145-153, 2003.

[12] A. Fakharuddin, R. Jose, T. M. Brown, F. Fabregat-Santiago, and J. Bisquert, "A perspective on the production of dye-sensitized solar modules," Energy and Environmental Science, vol. 7, no. 12, pp. 3952-3981, 2014.
[13] E. Olsen, G. Hagen, and S. Eric Lindquist, "Dissolution of platinum in methoxy propionitrile containing LiI/ $\mathrm{I}_{2}$," Solar Energy Materials and Solar Cells, vol. 63, no. 3, pp. 267-273, 2000.

[14] S. E. Bourdo and T. Viswanathan, "Graphite/Polyaniline (GP) composites: synthesis and characterization," Carbon, vol. 43, no. 14, pp. 2983-2988, 2005.

[15] X. Li, Y. S. Wei, Q. Q. Jin, and T. Z. Ren, "Expanded graphite/carbon nanotube as counter electrode for DSSCs," Advanced Materials Research, vol. 311-313, pp. 1246-1249, 2011.

[16] K. Aitola, J. Halme, N. Halonen et al., "Comparison of dye solar cell counter electrodes based on different carbon nanostructures," Thin Solid Films, vol. 519, no. 22, pp. 8125-8134, 2011.

[17] J. D. Roy-Mayhew, D. J. Bozym, C. Punckt, and I. A. Aksay, "Functionalized graphene as a catalytic counter electrode in dye-sensitized solar cells," ACS Nano, vol. 4, no. 10, pp. 62036211, 2010.

[18] M. Wu, X. Lin, T. Wang, J. Qiu, and T. Ma, "Low-cost dyesensitized solar cell based on nine kinds of carbon counter electrodes," Energy and Environmental Science, vol. 4, no. 6, pp. 2308-2315, 2011.

[19] J. G. Nam, Y. J. Park, B. S. Kim, and J. S. Lee, "Enhancement of the efficiency of dye-sensitized solar cell by utilizing carbon nanotube counter electrode," Scripta Materialia, vol. 62, no. 3, pp. 148-150, 2010.

[20] M. Kouhnavard, N. A. Ludin, B. V. Ghaffari, K. Sopian, and S. Ikeda, "Carbonaceous materials and their advances as a counter electrode in dye-sensitized solar cells: challenges and prospects," ChemSusChem, vol. 8, pp. 1510-1533, 2015.

[21] G. Veerappan, K. Bojan, and S.-W. Rhee, "Sub-micrometersized graphite as a conducting and catalytic counter electrode for dye-sensitized solar cells," ACS Applied Materials and Interfaces, vol. 3, no. 3, pp. 857-862, 2011.

[22] S. Ikeda, S. Kawasaki, Y. Hayashi et al., "Preparation of hydrophilic nano-carbon particles by electrolysis and their environmental applications," ECS Meeting Abstracts, abstract MA2012-02 3523, 2012.

[23] S. Ikeda, S. Kawasaki, A. Nobumoto et al., "Preparation and applications of hydrophilic nano-carbon particles," Advanced Materials Research, vol. 832, pp. 767-772, 2014.

[24] M. Kouhnavard, N. A. Ludin, B. V. Ghaffari, S. Ikeda, K. Sopian, and M. Miyake, "Hydrophilic carbon/ $/ \mathrm{TiO}_{2}$ colloid composite: a potential counter electrode for dye-sensitized solar cells," Journal of Applied Electrochemistry, vol. 46, no. 2, pp. 259-266, 2016.

[25] Ceramic Industry, Advanced Forming: Advances in Tape Casting Technology, 2001.

[26] F. Padinger, C. J. Brabec, T. Fromherz, J. C. Hummelen, and N. S. Sariciftci, "Fabrication of large area photovoltaic devices containing various blends of polymer and fullerene derivatives by using the doctor blade technique," Opto-Electronics Review, vol. 8, no. 4, pp. 280-283, 2000.

[27] N. Papageorgiou, W. F. Maier, and M. Grätzel, "An iodine/ triiodide reduction electrocatalyst for aqueous and organic media," Journal of the Electrochemical Society, vol. 144, no. 3, pp. 876-884, 1997.

[28] S. Mukherjee, B. Ramalingam, L. Griggs et al., "Ultrafine sputter-deposited Pt nanoparticles for triiodide reduction in dye-sensitized solar cells: Impact of nanoparticle size, crystallinity and surface coverage on catalytic activity," Nanotechnology, vol. 23, no. 48, Article ID 485405, 2012. 
[29] T. N. Murakami and M. Grätzel, "Counter electrodes for DSC: application of functional materials as catalysts," Inorganica Chimica Acta, vol. 361, no. 3, pp. 572-580, 2008.

[30] S. H. Huh, S.-H. Choi, and H.-M. Ju, “Thickness-dependent solar power conversion efficiencies of catalytic graphene oxide films in dye-sensitized solar cells," Current Applied Physics, vol. 11, no. 3, pp. S352-S355, 2011.

[31] X. Fang, T. Ma, G. Guan, M. Akiyama, T. Kida, and E. Abe, "Effect of the thickness of the Pt film coated on a counter electrode on the performance of a dye-sensitized solar cell," Journal of Electroanalytical Chemistry, vol. 570, no. 2, pp. 257263, 2004.

[32] K. Imoto, K. Takahashi, T. Yamaguchi, T. Komura, J.-I. Nakamura, and K. Murata, "High-performance carbon counter electrode for dye-sensitized solar cells," Solar Energy Materials and Solar Cells, vol. 79, no. 4, pp. 459-469, 2003.

[33] P. Joshi, L. Zhang, Q. Chen, D. Galipeau, H. Fong, and Q. Qiao, "Electrospun carbon nanofibers as low-cost counter electrode for dye-sensitized solar cells," ACS Applied Materials and Interfaces, vol. 2, no. 12, pp. 3572-3577, 2010. 

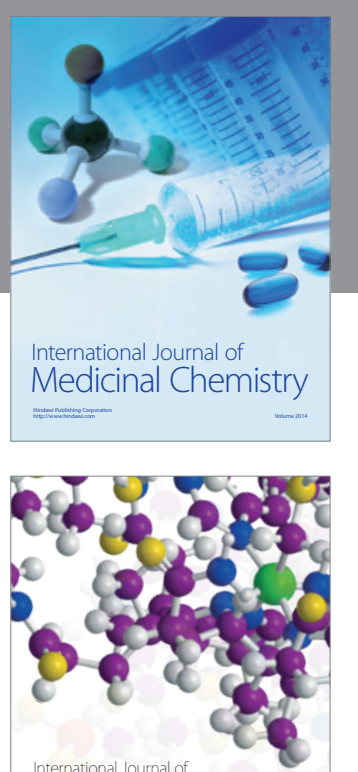

Carbohydrate Chemistry

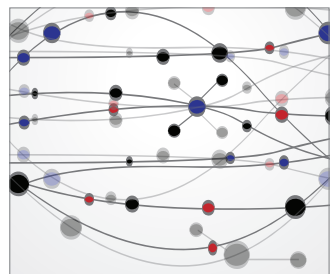

The Scientific World Journal
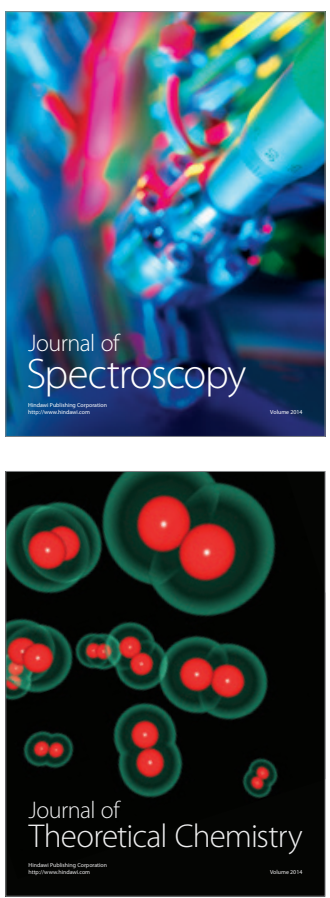


Submit your manuscripts at

http://www.hindawi.com

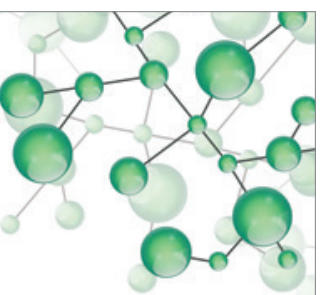

International Journal of

Inorganic Chemistry

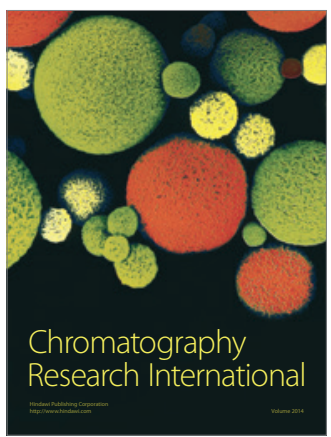

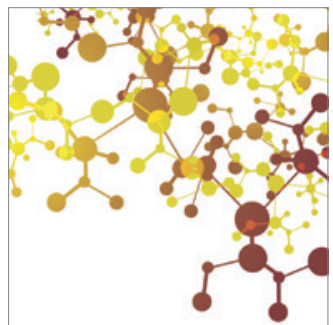

Applied Chemistry
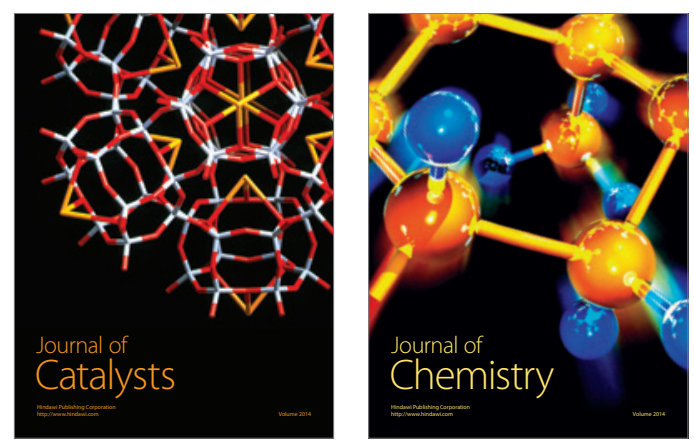
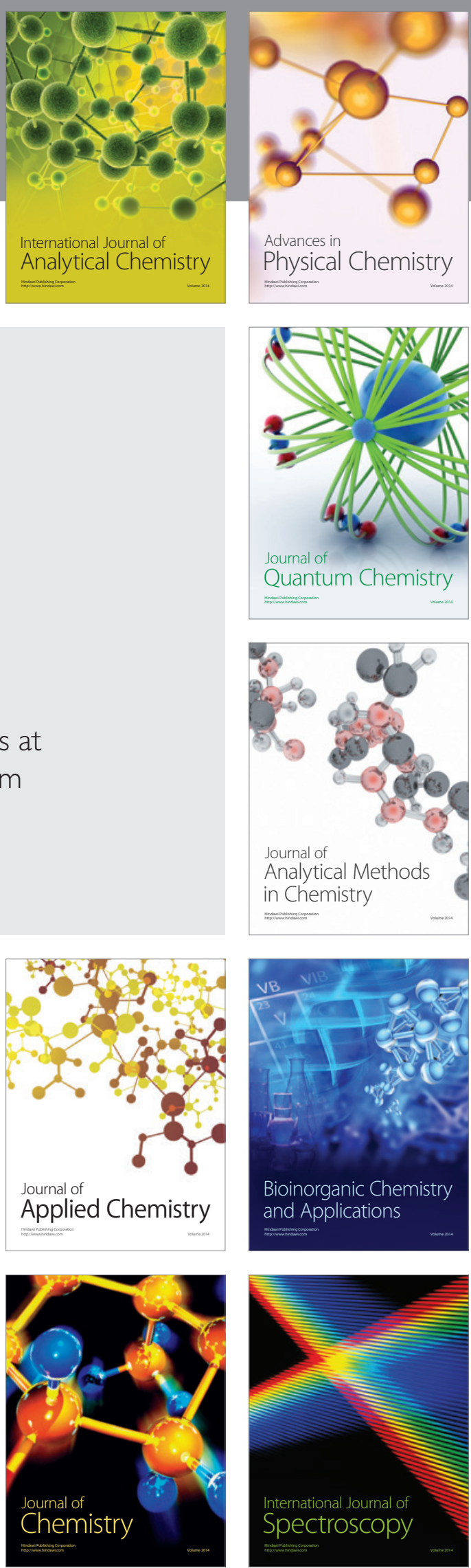